\title{
FIERY1 encoding an inositol polyphosphate 1-phosphatase is a negative regulator of abscisic acid and stress signaling in Arabidopsis
}

\author{
Liming Xiong, Byeong-ha Lee, Manabu Ishitani, Hojoung Lee, Changqing Zhang, \\ and Jian-Kang Zhu' \\ Department of Plant Sciences, University of Arizona, Tucson, Arizona 85721, USA
}

The plant hormone abscisic acid (ABA) plays a wide range of important roles in plant growth and development, including embryogenesis, seed dormancy, root and shoot growth, transpiration, and stress tolerance. ABA and various abiotic stresses also activate the expression of numerous plant genes through undefined signaling pathways. To gain insight into ABA and stress signal transduction, we conducted a genetic screen based on ABA- and stress-inducible gene transcription. Here we report the identification of an Arabidopsis mutation, fiery1 (fry1), which results in super-induction of ABA- and stress-responsive genes. Seed germination and postembryonic development of fry 1 are more sensitive to ABA or stress inhibition. The mutant plants are also compromised in tolerance to freezing, drought, and salt stresses. Map-based cloning revealed that FRY1 encodes an inositol polyphosphate 1-phosphatase, which functions in the catabolism of inositol 1, 4, 5-trisphosphate $\left(\mathrm{IP}_{3}\right)$. Upon ABA treatment, fry1 mutant plants accumulated more $\mathrm{IP}_{3}$ than did the wild-type plants. These results provide the first genetic evidence indicating that phosphoinositols mediate ABA and stress signal transduction in plants and their turnover is critical for attenuating ABA and stress signaling.

[Key Words: Abscisic acid; cold stress; salt stress; inositol polyphosphate 1-phosphatase; $\mathrm{IP}_{3 ;}$ gene regulation]

Received February 27, 2001; revised version accepted June 11, 2001.

The growth and development of plants are profoundly affected by environmental conditions. Through evolution plants have acquired adaptive strategies to cope with adverse environmental conditions, such as freezing temperatures, drought, and salt stress. One important regulator that coordinates plant developmental programs with environmental stress responses is the plant hormone abscisic acid (ABA). ABA plays essential roles in many physiological processes, such as embryogenesis, seed dormancy, leaf transpiration, and stress tolerance (Koornneef et al. 1998; Leung and Giraudat 1998). Under normal physiological conditions, ABA content in plants is quite low. However, ABA level can dramatically increase during late stages of embryogenesis and when plants are subjected to drought or salt stress (Koornneef et al. 1998; Leung and Giraudat 1998).

Genetic analysis of ABA signal transduction has been conducted mainly by using the property of ABA inhibition of seed germination. Seed germination-based ge-

${ }^{1}$ Corresponding author.

E-MAIL jkzhu@ag.arizona.edu; FAX (520) 621-7186.

Article and publication are at http://www.genesdev.org/cgi/doi/10.1101/ gad.891901. netic screens have identified mutants affected in ABA biosynthesis or sensitivity. The latter include ABA-insensitive mutants $(a b i)$ and ABA-hypersensitive mutants. The $A B I 1$ and $A B I 2$ genes encode homologous type $2 \mathrm{C}$ serine/threonine protein phosphatases (for review, see Leung and Giraudat 1998). The two genes have overlapping functions during seed development, seed dormancy, and leaf transpiration. Consistent with observations from mutational analysis of the ABIl protein (Sheen 1998), recent analysis of recessive abi1 mutant alleles showed that $A B I 1$ is indeed a negative regulator of ABA signaling, as indicated by the enhanced sensitivity of the recessive mutants to ABA in seeds and in vegetative tissues (Gosti et al. 1999). The other three $A B I$ genes, $A B I 3, A B I 4$, and $A B I 5$, all encode putative transcription factors (Giraudat et al. 1992; Finkelstein and Lynch 2000) and their roles in regulating ABA responses are seed-specific. Interestingly, an independent genetic screen identified a glucose insensitive locus, GIN6, which was found to be identical to $A B I 4$ (Arenas-Huertero et al. 2000). Characterization of other abi mutants revealed that $A B I 5$ also participates in glucose signal transduction during postembryonic development (Arenas-Huertero et al. 2000). 
The other group of ABA-signaling mutants is represented by the enhanced response to $A B A$ (era) mutations. ERA1 encodes the $\beta$ subunit of farnesyl transferase, implying that an as-yet-unknown protein(s) in ABA signaling needs to be farnesylated (Cutler et al. 1996). Recently, an additional ERA locus, ERA3, was found to be identical to EIN2 (Ghassemian et al. 2000). ein2 mutations also suppressed the sensitivity of $a b i 1-1$ to ABA in germination (Beaudoin et al. 2000). Analysis of several ethylene response mutants showed that ethylene counteracts ABA signaling during seed germination; whereas it positively regulates $\mathrm{ABA}$ action in root growth (Beaudoin et al. 2000; Ghassemian et al. 2000).

In vegetative tissues, $\mathrm{ABA}$ and various abiotic stresses activate the expression of a large number of plant genes, which may play important roles in stress adaptation (Zhu et al. 1997). Recent molecular and genetic analysis suggests that stress-activated gene transcription is mediated by both ABA-dependent and ABA-independent signaling pathways. Analysis of stress-gene expression in ABA-deficient and ABA-insensitive mutants indicated that some stress genes are activated independently of ABA. These gene promoters contain a cis-acting DNA regulatory element, termed the dehydration-responsive element (DRE)/CRT, which responds to cold or osmotic stress but not to ABA (Yamaguchi-Shinozaki and Shinozaki 1994). In contrast, the ABA responsive element/ complex (ABRE) found in these promoters mediates gene expression in response to ABA (Shen and Ho 1995).

We developed a system to screen for mutants with altered responses to ABA, drought, salt and/or cold stress by utilizing Arabidopsis thaliana plants that were engineered to emit bioluminescence in response to the phytohormone or to various abiotic stresses (Ishitani et al. 1997). The bioluminescent plants contain the firefly luciferase reporter gene under control of the RD29A promoter (RD29A-LUC) that contains both the DRE/CRT and the ABRE elements and is responsive to ABA, hyperosmotic stress, and cold. Here we present the identification of one mutation, fiery1 (fry1), which results in dramatically enhanced expression of ABA- and stressresponsive genes when treated with $\mathrm{ABA}$, low temperature, drought, or salt stress. Map-based cloning revealed that FRY1 encodes an inositol polyphosphate 1-phosphatase, which functions in the catabolism of the second messenger inositol 1, 4, 5-trisphosphate. These results strongly suggest the inositol phosphate module as an early signaling module that functions in both ABA and environmental stress signaling pathways. Our work also reveals an important mechanism for the control of ABA and stress response amplitude and sensitivity by FRY1mediated turnover of phosphoinositols.

\section{Results}

Isolation of Arabidopsis mutants that exhibit super-induction of $A B A$ - and stress-responsive bioluminescence

Arabidopsis plants expressing the RD29A-LUC transgene were mutagenized with ethyl methane sulfonate
(EMS) and mutants were screened for their aberrant bioluminescence in response to low temperature, osmotic stress, or ABA treatment (Ishitani et al. 1997). One group of mutants that exhibited enhanced luminescence expression when treated with either cold, $\mathrm{NaCl}$, or ABA were isolated. Two allelic mutants were chosen for detailed characterization. Figure 1 presents the luminescence images of the wild type and mutant seedlings before treatment (Fig. 1B) and after being treated with cold (Fig. 1C), ABA (Fig. 1D), and $\mathrm{NaCl}$ (Fig. 1F). Because of its strong luminescence phenotype, the mutant was named fiery1 (fry1). Quantitation of the luminescence intensity of the images indicated that the luminescence intensities in the fry 1-1 mutant are about three to four times higher than in the wild-type plants when treated with either cold, $\mathrm{NaCl}$, polyethylene glycol (PEG), or ABA (Fig. 1G). Without stress treatment, fry1 plants exhibited some basal RD29A-LUC expression; whereas the wild type did not (Fig. 1B). The low level of luminescence in untreated fry1-1 mutant plants was likely induced by changes in humidity or other mild perturbations in the environment during experimental manipulation.

The fry1 mutants were backcrossed with the wild-type plants. Luminescence analysis of the resulting $\mathrm{F}_{1}$ and selfed $\mathrm{F}_{2}$ progenies under cold or ABA treatments indicated that fry 1 is a recessive, single nuclear mutation (data not shown). Pairwise crosses among the mutants with similar enhanced luminescence phenotypes identified another fry1 allele, fry 1-2 (data not shown). Both fry1 mutants have leaves that are more serrated than wildtype leaves but otherwise do not show obvious developmental defects (data not shown).

\section{Enhanced expression of $A B A$ - and stress-responsive genes in fryl mutant plants}

To determine whether the expression of endogenous $R D 29 A$ and other stress-responsive genes is affected by the fry1 mutation, total RNA from fry1-1 mutant, and wild-type plants treated with cold, $\mathrm{NaCl}, \mathrm{PEG}$, or ABA was analyzed by Northern hybridization. Consistent with the luciferase imaging results, the steady-state level of $R D 29 A$ transcripts was higher in the mutant than in the wild type under any of the treatments (Fig. 2A).

The fry 1 mutation also increased the expression of other stress-responsive genes examined under low temperature, osmotic stress or ABA treatment (Fig. 2A). These genes include KIN1 (GenBank accession no. X51474), COR15A (GenBank accession no. U01377), ADH (alcohol dehydrogenase; GenBank accession no. M12196), and HSP70 (GenBank accession no. AF217459). Without ABA or stress treatment, there was also some basal expression of the endogenous RD29A gene in fry1-1 mutant plants, consistent with the RD29A-LUC phenotype (Fig. 1B). We also note that in the fry 1 mutant treated with either ABA, $\mathrm{NaCl}$, or PEG, the abundance of HSP70 transcript is lower $1 \mathrm{~h}$ after treatment than $0.5 \mathrm{~h}$ after treatment (Fig. 2A). This is also true for COR15A expression in response to ABA or PEG. 
A

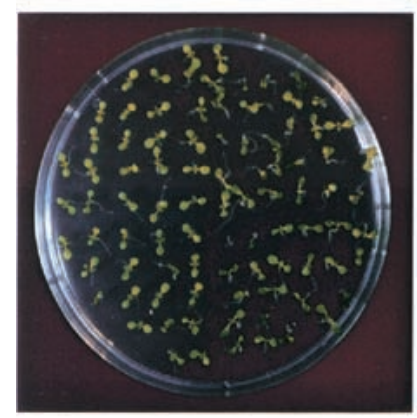

E

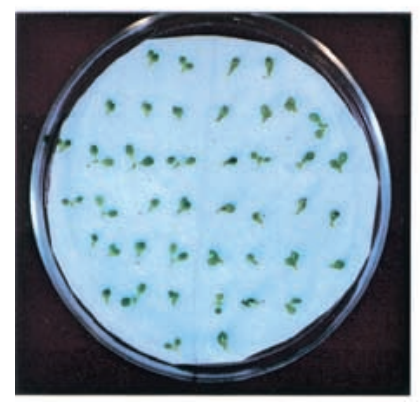

B

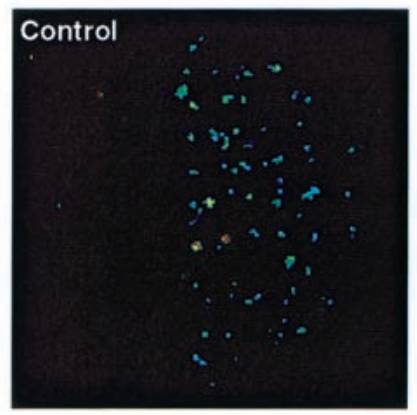

$\mathbf{F}$

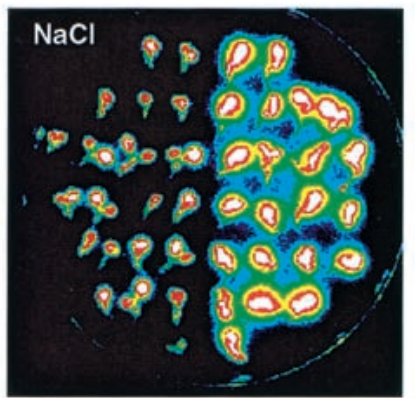

C

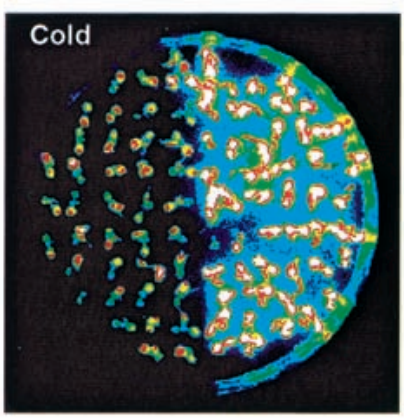

G

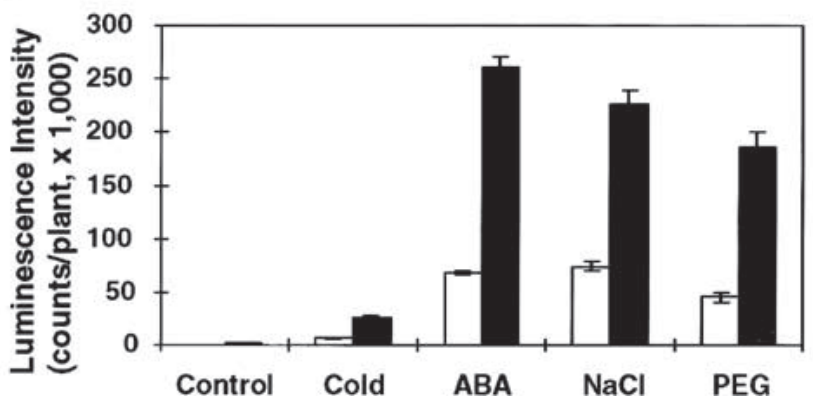

Figure 1. The fry1 mutation enhances RD29A-LUC expression in response to cold, ABA, or hyperosmotic stress treatment. RD29A$L U C$ expression was quantitatively measured as luminescence intensity. (A) Wild-type (left) and fry1-1 (right) seedlings grown in an agar plate. $(B)$ Luminescence without stress or ABA treatment. $(C)$ Luminescence after low-temperature treatment at $0^{\circ} \mathrm{C}$ for $24 \mathrm{~h}$. $(D)$ Luminescence after treatment with $100 \mu \mathrm{M}$ ABA for $3 \mathrm{~h}$. (E) Wild-type (left) and fry1-1 (right) seedlings on filter paper saturated with $300 \mathrm{mM} \mathrm{NaCl}$. $(F)$ Luminescence of $(E)$ after 3-h treatment. The color scale at right shows the luminescence intensity from dark blue (lowest) to white (highest). (G) Quantitation of the luminescence intensities of wild-type and fry1-1 plants in $(B)(\mathrm{control}),(C)(\mathrm{cold})$, $(D)(\mathrm{ABA})$, and $(F)(\mathrm{NaCl})$. Also shown is $30 \%$ polyethylene glycol (PEG) treatment (for $5 \mathrm{~h}$ ). Data represent means and standard errors $(n=20)$. Open bars, wild type; black bars, fry1-1.

Another ABA- and stress-regulated gene, COR47/GenBank accession no. X59814), exhibited strong constitutive expression in fry 1-1 mutant plants; whereas it was expressed only under induced conditions in the wildtype plants (Fig. 2A). Interestingly, COR47 expression under ABA or the stress treatments was not substantially different between fry1-1 and wild-type plants (Fig. 2A). As a control, the expression of an actin gene in the mutant and wild-type plants was also examined. The state-steady transcript levels of actin were not significantly regulated by $\mathrm{ABA}$ or the stress treatments and not substantially different between fry1-1 and wild-type plants (Fig. 2A).

Because CBF/DBEB1 transcription factors are able to activate some of these stress-responsive genes and the expression levels of the transcription factors themselves are regulated by stress, we examined the expression of one of the CBF genes, CBF2 (GenBank accession no. AF074601), which has the highest induction under lowtemperature treatments. The results indicate that $C B F 2$ expression was induced by cold treatments and the expression levels are not substantially different between wild type and fry1-1 for either 1.5 or $3 \mathrm{~h}$ of cold treatment (Fig. 2B). Whereas CBF2 expression in wild type is transient and its transcript level decreased drastically after $6 \mathrm{~h}$ of cold treatment as reported (Medina et al. 1999; Lee et al. 2001), the expression in fry1-1 is more sus- tained. Quantitation indicates that CBF2 transcript level in fry 1 for a 6-h cold treatment was 1.8 times higher than that in the wild-type plants (Fig. 2B).

fryl mutation reduces the thresholds of gene induction by $A B A$ and stress

The luminescence images (Fig. 1) and RNA blot analysis (Fig. 2) indicated that fry1 mutations significantly increase the amplitude of stress-regulated gene expression. To determine whether the sensitivity of fry1 plants to low temperature, osmotic stress or ABA is also altered, we assayed the luminescence of the plants under different treatment dosages (Fig. 3A-C). At room temperature $\left(23^{\circ}+1^{\circ} \mathrm{C}\right)$ or $18^{\circ} \mathrm{C}$, neither fry $1-1$ nor wild-type seedlings showed any high-level RD29A-LUC expression. At $15^{\circ} \mathrm{C}$. However, fry 1-1 plants exhibited a clear induction of RD29A-LUC; whereas the wild type still did not show any measurable expression. With further decreases in the treatment temperature, the wild-type plants began to show an induction of RD29A-LUC while the expression in fry 1-1 plants increased substantially (Fig. $3 \mathrm{~A}$ ). At $0^{\circ} \mathrm{C}$, the luminescence intensity in fry1-1 was $\sim 5$ times as high as that in the wild-type plants. With a further decrease in temperature $\left(-5^{\circ} \mathrm{C}\right.$ for $\left.2 \mathrm{~h}\right)$, the luminescence intensity in fry 1-1 plants was $\sim 20$ times that of the wildtype level (data not shown). 


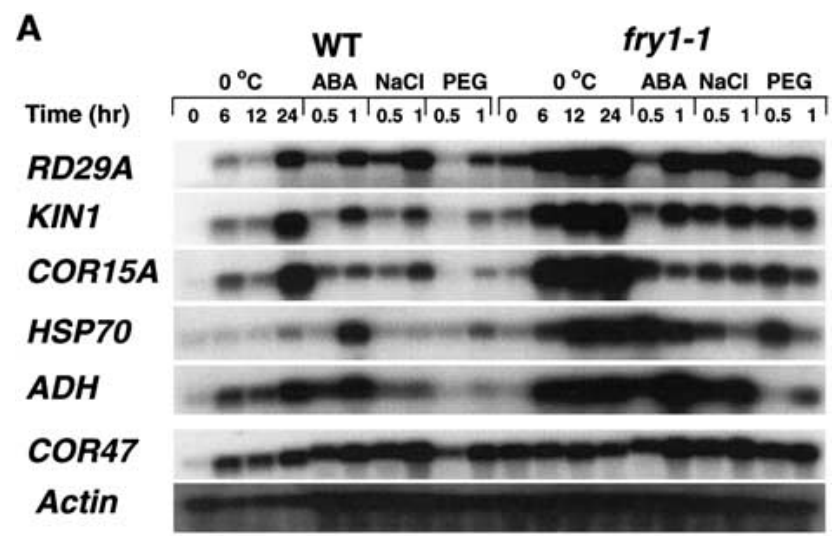

B

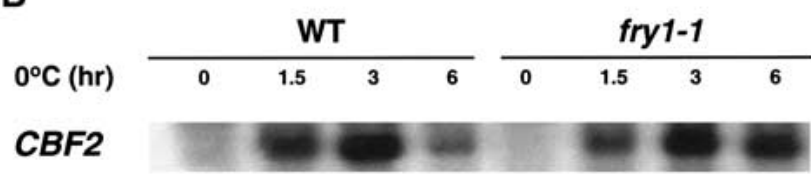

Tubulin

Figure 2. Transcript levels of stress-responsive genes in fry1-1 and wild-type plants. Plants were treated for the indicated times with low temperature $\left(0^{\circ} \mathrm{C}\right), 100 \mu \mathrm{M} \mathrm{ABA}, 300 \mathrm{mM} \mathrm{NaCl}$, or $30 \%$ PEG. Actin and tubulin genes were used as loading controls. WT, wild type.

In the wild-type plants, treatment with $0.1 \mu \mathrm{M}$ ABA did not induce obvious expression of RD29A-LUC (Fig. $3 \mathrm{~B})$. On the contrary, a significant expression of the reporter gene was induced by $0.1 \mu \mathrm{M}$ ABA in fry $1-1$ plants. In both wild-type and fry1-1 plants, the level of RD29A$L U C$ expression increased with increases in ABA concentration. At $100 \mu \mathrm{M}$, the luminescence intensity in fry1-1 plants is about four times higher than in the wild type. Similarly, the induction of RD29A-LUC was evident in fry1-1 plants when treated with as low as $10 \mathrm{mM}$ $\mathrm{NaCl}$; whereas in the wild-type plants, an obvious induction only occurred at $\mathrm{NaCl}$ concentrations of 100 $\mathrm{mM}$ or higher (Fig. 3C). The highest expression was found at $300 \mathrm{mM} \mathrm{NaCl}$ with both wild-type and fry1-1 plants. With further increases in $\mathrm{NaCl}$ concentration, the expression level decreased rapidly, probably due to stress damage to basic cellular functions (Fig. 3C).

The slopes of the dosage response curves for fry 1-1 mutant plants are substantially steeper than the corresponding ones for wild-type plants (Fig. 3A-C). This is true for all three treatments (i.e., low temperature, ABA, and $\mathrm{NaCl}$ ). These results show that the enhanced stress and $\mathrm{ABA}$ responses seen in fry 1 mutants are results of increased sensitivity to the stimulations rather than simply proportional amplification with increasing stimulation strength.

Despite the increased sensitivity and higher response amplitude, the induction kinetics in fry1-1 mutant plants is similar to that in the wild type (Fig. 3D-F). Time courses of low temperature, $\mathrm{ABA}$, and $\mathrm{NaCl}$ responses are presented in Fig. 3D, 3E, and 3F, respectively. It can be seen that the levels of RD29A-LUC expression in fry 1-1 plants are consistently higher throughout the time courses (Fig. 3D-F).

\section{Germination of fryl mutant seeds is more sensitive to $A B A$ and osmotic stress}

In the absence of exogenous ABA, the germination of fry1-1 mutant seeds was delayed in comparison with the wild type, reflecting an enhanced sensitivity of the mutant seeds to endogenous ABA (Fig. 4A,C). In the presence of $1 \mu \mathrm{M}$ ABA, fry1-1 seed germination was further delayed and the germination rate was reduced to $<80 \%$ (Fig. 4B). In contrast, wild-type seeds reached near $100 \%$ germination rate in the presence of $1 \mu \mathrm{M}$ ABA (Fig. 4B). ABA dose-response curves show that lower concentrations of ABA also had more inhibition on germination of fry1 seeds (Fig. 4C). Similarly, $50 \mathrm{mM} \mathrm{NaCl}$ reduced germination rate by $50 \%$ for fry $1-1$ seeds but did not substantially affect the germination of wild-type seeds (Fig. $4 \mathrm{E})$. In addition to a reduced rate of seed germination, ABA also inhibited the growth and the greening of cotyledons of fry1-1 mutant seedlings. In the presence of 1 $\mu \mathrm{M}$ ABA in agar medium, although the radicles of most fry1-1 seeds emerged, the seedlings failed to grow (Fig. 4D). These results indicate that fry 1-1 mutant plants are more sensitive to osmotic stress and ABA during seed germination and early seedling development.

\section{fryl mutant plants are defective in cold acclimation}

The high sensitivity of RD29A-LUC expression to low temperature and the enhanced expression of cold-regulated genes in fry 1-1 plants may have an impact on cold acclimation (i.e., the development of freezing tolerance). We determined freezing-induced electrolyte leakage in detached leaves as an indicator of freezing-induced injury. Without cold acclimation, fry1 leaves showed slightly more electrolyte leakage than the wild type. The temperatures at which $50 \%$ electrolyte leakage occurred $\left(\mathrm{LT}_{50}\right)$ were $\sim-2.5^{\circ} \mathrm{C}$ and $-3.8^{\circ} \mathrm{C}$ for fry $1-1$ and wild-type plants, respectively (Fig. 5A).

After a 7 -d incubation at $4^{\circ} \mathrm{C}$ (i.e., cold acclimation), the freezing tolerance of wild-type plants increased significantly, as can be seen in the reduced electrolyte leakage (Fig. 5A). The $\mathrm{LT}_{50}$ for the cold acclimated wild-type plants dropped to $\sim-9.4^{\circ} \mathrm{C}$ (Fig. 5A). In contrast, fry $1-1$ mutant plants showed only a slight increase in freezing tolerance after cold acclimation. The $\mathrm{LT}_{50}$ value for coldacclimated fry $1-1$ plants is $\sim-5.0^{\circ} \mathrm{C}$, which is $>4.4^{\circ} \mathrm{C}$ higher than that of the wild type.

\section{fryl mutant seedlings are more sensitive to osmotic stress inhibition}

The sensitivity of fry 1 plants to osmotic stress was tested by growing seedlings on agar plates containing Murashige-Skoog (MS) nutrients supplemented with mannitol or $\mathrm{NaCl}$. fry1-1 Mutant seedlings were clearly more sensitive to $\mathrm{NaCl}$ (Fig. 5B) or mannitol stress (Fig. 5C). On medium containing MS nutrients only or MS plus $50 \mathrm{mM} \mathrm{NaCl}$ or $100 \mathrm{mM}$ mannitol, both fry1-1 and wild-type plants had healthy green cotyledons. On 100 

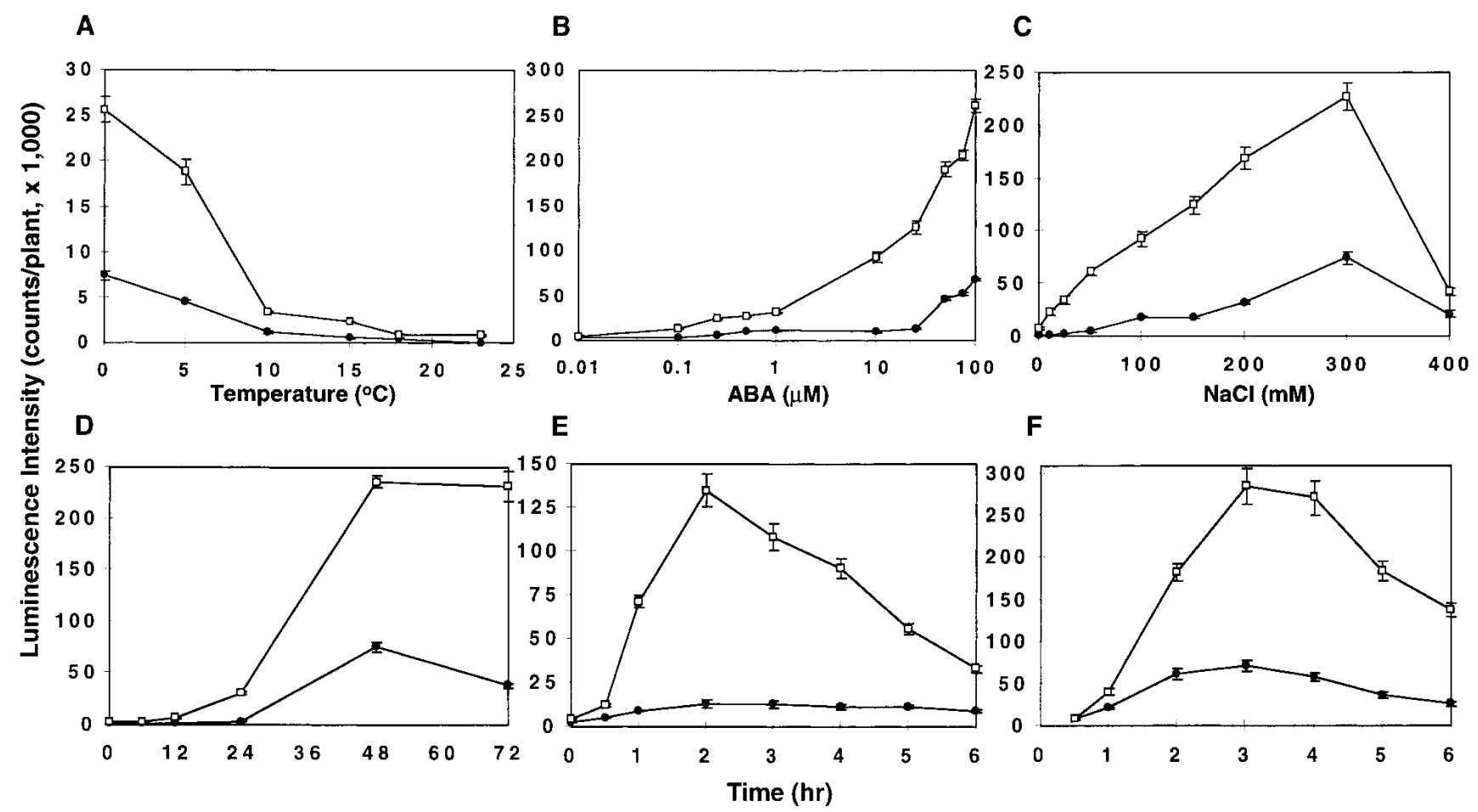

Figure 3. Dose-response $(A-C)$ and time course $(D-F)$ of $R D 29 A-L U C$ induction by temperature $(A, D), A B A(B, E)$ or salt stress $(C, F)$ in wild-type and fry1-1 plants. For the dosage response assay, the treatment durations were $24 \mathrm{~h}$ for the temperature treatment $(A), 3$ $\mathrm{h}$ for the $\mathrm{ABA}$ treatment $(B)$, and $4 \mathrm{~h}$ for the $\mathrm{NaCl}$ treatment $(C)$. For time-course analyses, the dosages were $0^{\circ} \mathrm{C}$ for the cold treatment $(D), 100 \mu \mathrm{M} \mathrm{ABA}(E)$, and $300 \mathrm{mM} \mathrm{NaCl}(F)$. Data represent means and standard errors $(n=20)$. Closed circles, wild type; open squares, fry1-1.

$\mathrm{mM} \mathrm{NaCl}$ medium, none of the wild-type plants had yellow cotyledons; whereas nearly $80 \%$ of fry $1-1$ mutant plants had cotyledons that became yellowish (Fig. 5B). When the $\mathrm{NaCl}$ concentration was increased to $150 \mathrm{mM}$, the cotyledons of most fry1-1 plants but not wild-type plants died (Fig. 5B). At $200 \mathrm{mM} \mathrm{NaCl}$, almost all fry1-1 seedlings were killed. However, $\sim 90 \%$ of wild-type seedlings survived the $200 \mathrm{mM} \mathrm{NaCl}$ treatment (Fig. 5B). Similarly, high concentrations of mannitol caused substantial damage to fry1-1 seedlings, as evidenced by the yellowing of cotyledons (Fig. 5C). The same concentrations of mannitol caused little or no visual damage to wild-type seedlings.

We treated fry1-1 and the wild-type seedling with PEG to mimic drought stress. Electrolyte leakage was measured to quantify the extent of damage caused by the treatment. Under control (water only) or 10\% PEG treatment, there was no difference in the percentage of electrolyte leakage between wild-type and fry1-1 plants (Fig. 5D). However, with higher concentrations of PEG, significantly more electrolytes were lost from fry1-1 plants than from the wild type. The results suggest that fry1-1 plants suffer more damage to the cell membrane under drought stress.

Transpiration rates in detached shoots of wild type and fry1-1 mutant plants were compared. No significant difference in transpirational water loss was found between fry1-1 and wild-type plants (data not shown), suggesting that FRY1 is not essential for stomatal regulation.

\section{Genetic mapping of the fryl mutation}

To genetically map the FRY1 gene, fry1-1 mutant plants in the $\mathrm{C} 24$ ecotype were crossed with wild-type plants of the ecotype Columbia. From the segregating $\mathrm{F}_{2}$ population, fry 1 mutant seedlings were identified by enhanced luminescence under cold and ABA treatments. A mapping survey of markers distributed throughout the five Arabidopsis chromosomes revealed that FRY1 is linked with nga129 near the bottom of chromosome V (Fig. 6A). We then localized FRY1 to a region between the SSLP markers K19B1 and MSN2 (Fig. 6A). Fine mapping delimited $F R Y 1$ to an $\sim 160$-kb region flanked by SSLP marker MBK5-64k and single nucleotide polymorphism marker MJH24-48k (Fig. 6A). Further mapping became very difficult due to a lack of recombination events.

To facilitate gene isolation, a large-scale T-DNA mutagenesis of the wild-type RD29A-LUC plants was carried out to isolate a tagged allele of fry1. We generated close to 50,000 transformants with an estimated average of 1.5 insertions/line. Among the T-DNA lines, one mutant was found to have phenotypes similar to those exhibited by fry 1 plants (i.e., enhanced RD29A-LUC expression under either cold, salt, or ABA treatment). This T-DNA mutant was crossed with fry1-1 plants. The $\mathrm{F}_{1}$ progenies were tested for bioluminescence in response to cold or ABA treatments and were found to be similar to the parental plants (data not shown). Therefore, this $\mathrm{T}$ DNA mutant is allelic to fry1-1 and is named fry1-3. 
A B

C

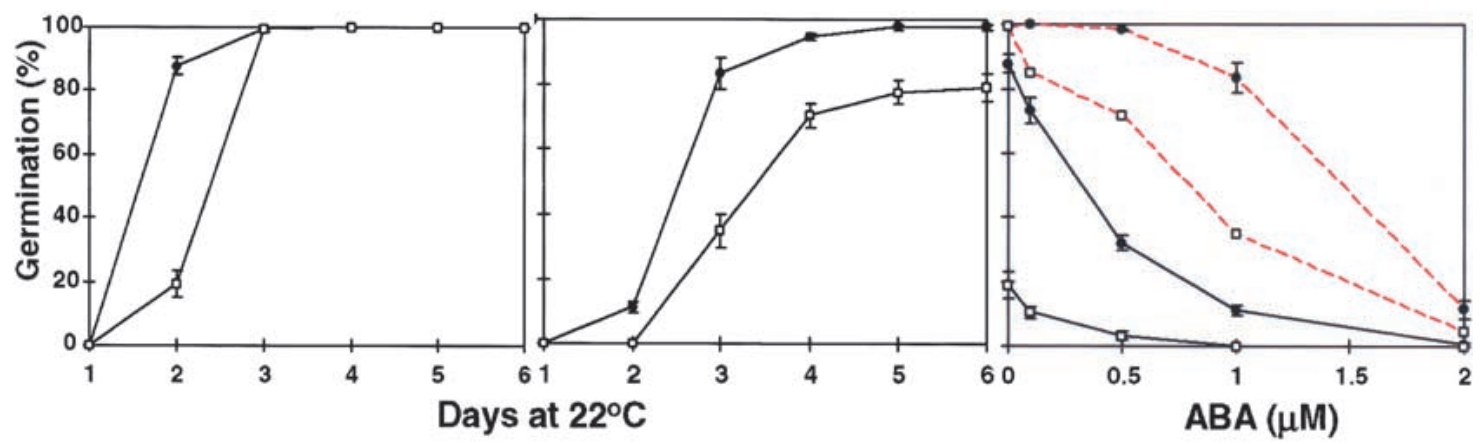

D

E
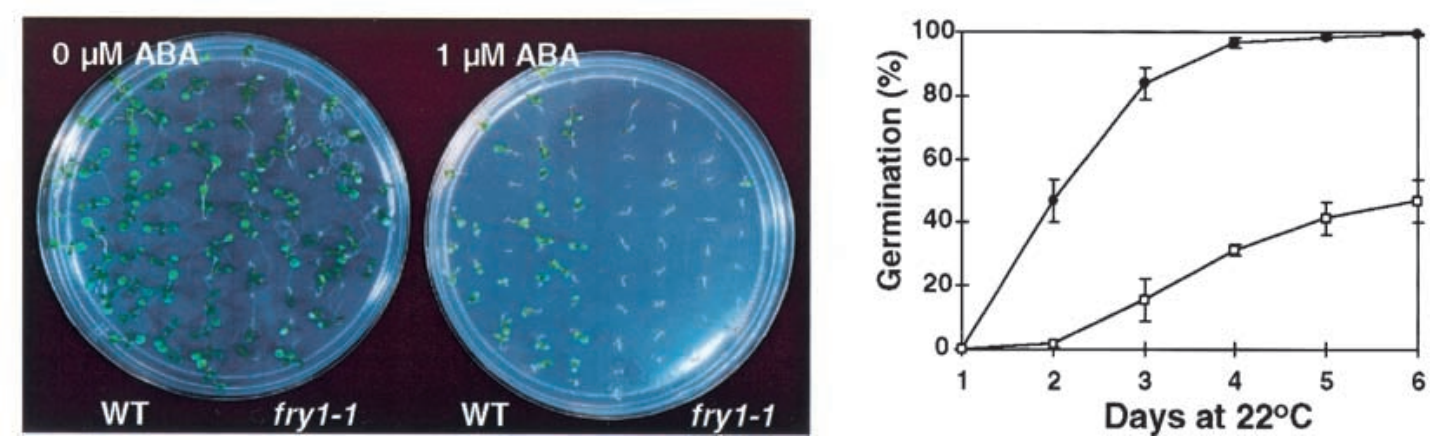

Figure 4. Seed germination and seedling development of wild type and fry1-1 in response to ABA or NaCl. $(A-C, E)$ Seeds on filter paper were incubated at $0^{\circ} \mathrm{C}$ for $48 \mathrm{~h}$ before being placed at $23^{\circ} \mathrm{C}$ for germination. $(A)$ Germination in the absence of $\mathrm{ABA}\left(\mathrm{H}_{2} \mathrm{O}\right.$ only); (B) Germination in the presence of $1.0 \mu \mathrm{M} \mathrm{ABA} ;(C)$ Germination at day 2 (solid lines) and day 3 (broken lines) in the presence of different concentrations of $\mathrm{ABA}_{1}(D)$ Inhibition of seedling development by ABA. Wild-type or fry1-1 mutant seeds on MS agar plates supplemented with (plate on the right) or without (plate on the left) $1.0 \mu \mathrm{M} \mathrm{ABA}$ were incubated at $0^{\circ} \mathrm{C}$ for $48 \mathrm{~h}$ before being placed at $23^{\circ} \mathrm{C}$ for germination. The picture was taken $10 \mathrm{~d}$ after incubation at $23^{\circ} \mathrm{C}$. (E) Germination in the presence of $50 \mathrm{mM} \mathrm{NaCl}$. Results are means and standard errors $(n=3)$. Closed circles, wild type; open squares, fry1-1.

Genetic analysis showed that the luminescence phenotypes of fry1-3 cosegregated with Basta resistance, suggesting that the FRY1 gene was tagged in this T-DNA mutant.

Arabidopsis DNA flanking the T-DNA insertion in fry1-3 plants was obtained by TAIL (thermal asymmetric interlaced) PCR (for left-border flanking DNA) and by plasmid rescue (for right-border flanking DNA; Weigel et al. 2000). The sequences of these flanking DNA fragments were found to match that of the predicted gene MBM17.8 on the P1 clone MBM17, consistent with the mapping location of $F R Y 1$ (Fig. 6A).

The MBM17.8 gene was amplified by PCR from fry1-1 and fry 1-2 mutant plants and sequenced. Single nucleotide mutations in the DNA sequence were found from both mutants that would result in changes in the predicated amino acid sequence (Fig. 6B). The wild-type MBM17.8 genomic DNA along with upstream sequence was cloned into a binary vector and transferred into fry1-1 mutant plants via Agrobacterium-mediated in planta transformation. One hundred fifty independent $\mathrm{T}_{1}$ transformants were tested for their ABA-responsive luminescence and 40 independent $\mathrm{T}_{2}$ lines were tested for cold, $\mathrm{NaCl}$, as well as ABA-responsive luminescence.
All transformants tested showed wild-type RD29A-LUC expression patterns (data not shown). These results show that MBM17.8 is FRY1.

FRY1 encodes a bifunctional enzyme with $3^{\prime}\left(2^{\prime}\right), 5^{\prime}$-bisphosphate nucleotidase and inositol polyphosphate 1-phosphatase activities

FRY1 cDNA was obtained by reverse transcriptase PCR and sequenced. BLAST searches indicated that the open reading frame of FRY1 is identical to the $S A L 1$ gene that encodes a bifunctional enzyme with $3^{\prime}\left(2^{\prime}\right), 5^{\prime}$-bisphosphate nucleotidase and inositol polyphosphate 1-phosphatase activities (Quintero et al. 1996). The SAL1 gene was initially isolated because it was capable of increasing the salt tolerance of yeast cells when expressed in yeast (Quintero et al. 1996). SAL1 is similar to several $\mathrm{Li}^{+}$ and $\mathrm{Na}^{+}$-sensitive $3^{\prime}\left(2^{\prime}\right), 5^{\prime}$-bisphosphate nucleotidases/ inositol polyphosphate 1-phosphatases (INPP), such as the yeast MET22/HAL2, Escherichia coli CysQ, and INPPs from mouse, Drosophila, and human (Fig. 6C,D). Among this group of proteins, FRY1 shows the highest similarity with four other open reading frames in Arabidopsis, as well as DNPP1 from rice. Interestingly, 
A

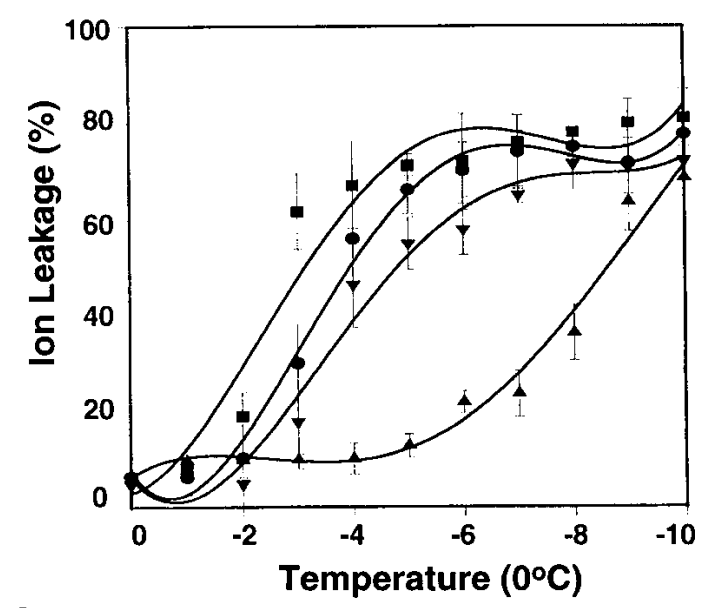

C

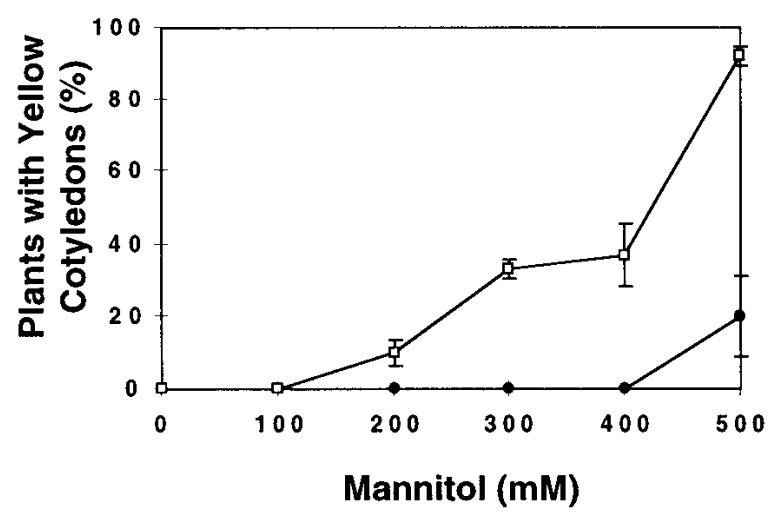

B

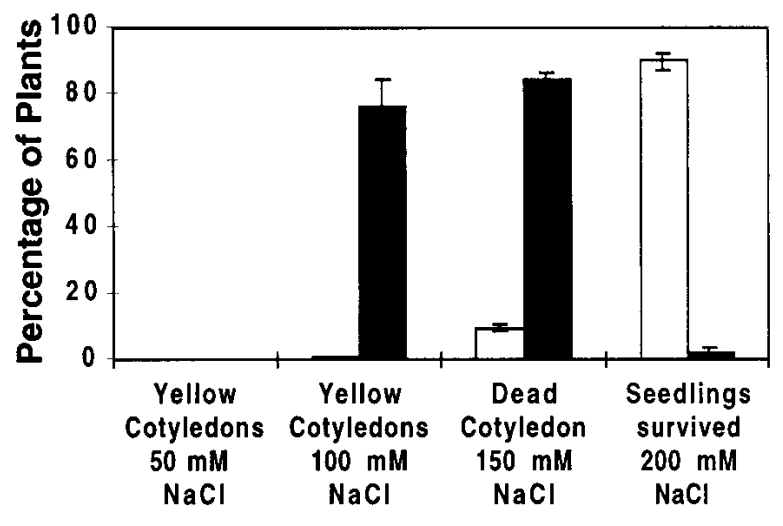

D

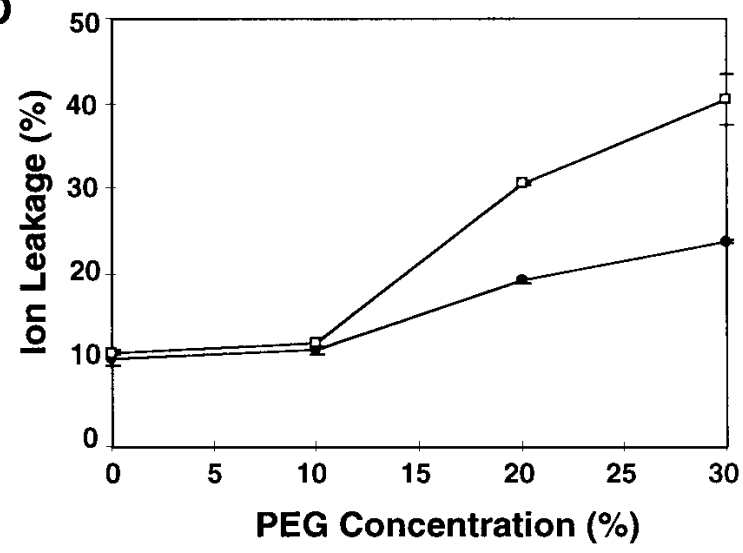

Figure 5. Compromised stress tolerance in fry1 mutant plants. (A) Freezing-induced electrolyte leakage in fry1-1 and wild-type plant leaves. Data are averages and standard deviations $(n=3)$. Wild type (solid square); fry1-1 (solid circle); wild type, cold-acclimated (solid up arrow); fry1-1, cold-acclimated (solid down arrow). (B-C) fry1-1 mutant seedlings suffer more damage as a result of hyperosmotic stress by $\mathrm{NaCl}$ or mannitol treatment. Shown are the percentages of seedlings with yellowish or bleached (dead) cotyledons on agar media supplemented with 50,100 , or $150 \mathrm{mM} \mathrm{NaCl}$ and the percentage of seedlings that survived $200 \mathrm{mM} \mathrm{NaCl}(B)$ and percentage of leaf damage on media supplemented with different concentrations of mannitol $(C)$. Data are the means of three separate experiments each with 80 seedlings from wild type or fry1-1. (D) Ion leakage from seedlings treated with PEG. Data are means of four independent assays and standard errors. In $B, C$, and $D$, black symbols refer to wild type and open symbols refer to fry 1-1.

FRY1 and two isologs, MBM17.9 (GenBank accession no. BAA96902) and MBM17.10 (GenBank accession no. Z83312), are arranged in tandem on chromosome V, presumably a result of duplications of a common ancestor. Phylogenetic analysis indicates that these plant isologs are more closely related to INPP1 from human and INPP from fruit fly than to others from lower organisms, such as CysQ from E. coli and MET22/HAL2 from yeast (data not shown).

In the fry 1-1 mutant, a G to A substitution in the sixth exon (Fig. 6B) creates a stop codon and thus truncates the protein at the beginning of the conserved $\alpha 5$ helix (Fig. 6D; York et al. 1995). The fry1-2 mutation is also a G to A substitution (Fig. 6B) that results in the replacement of the invariant negatively charged residue E72 (glutamic acid) to a positively charged amino acid $\mathrm{K}$ (lysine), in the conserved $\alpha 1$ region (Fig. 6C; York et al. 1995). The EE consensus in the $\beta 1$ sheet and the WD- $\mathrm{X}_{11}$-GG motif in the $\alpha 5$ helix are both required for the coordination of metal ions and phosphate and for nucleophilic water activation (York et al. 1995). Therefore, the fry1-1 mutation is most likely a null allele because the mutated protein is devoid of the $\alpha 5$ helix. In the fry $1-3$ allele, a T-DNA is inserted between the fifth and sixth exons and thus led to the disruption of the gene. RNA analysis showed that the FRY1 transcript is absent in the fry1-3 allele (Fig. 7A). Thus, fry1-3 mutation is also a null allele.

RNA blot analysis showed that FRY1 is expressed in every organ examined although the transcript abundance is not the same in all plant tissues (Fig. 7A). The expression level of FRY1 was not significantly affected by either stress or ABA treatment (Fig. 7B). FRY1 expression was also examined in plants expressing the FRY1::GUS transgene. Among 21 independent transformants tested, 17 lines showed GUS activity. Consistent with RNA 
Xiong et al.

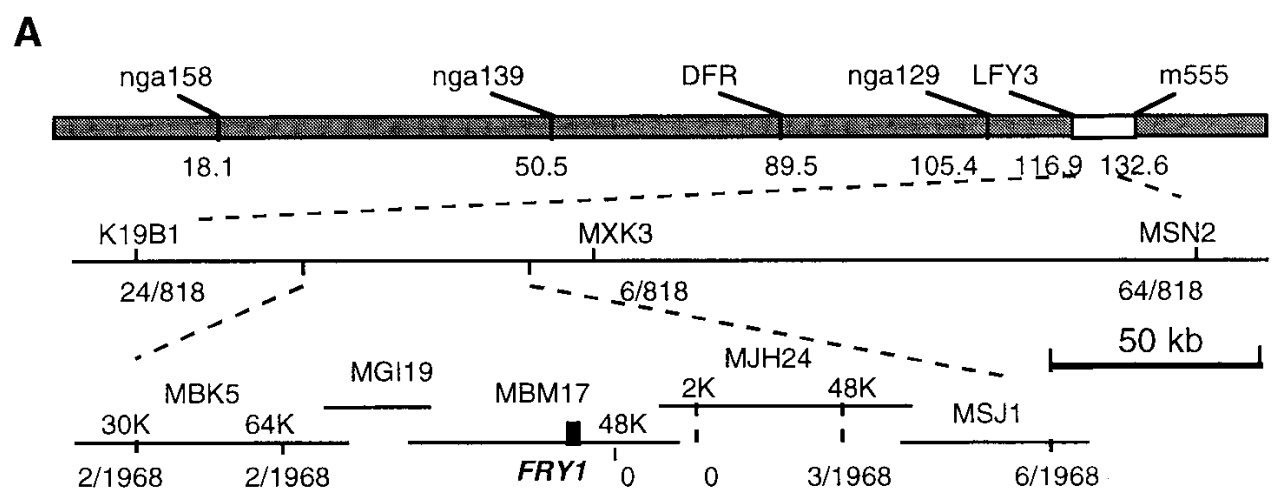

B

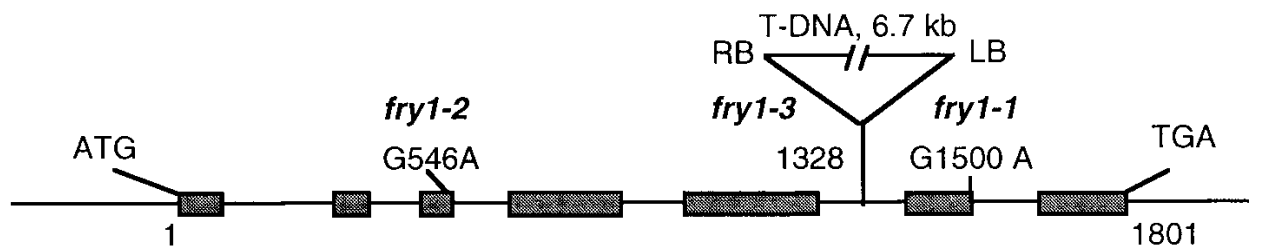

C

$\begin{array}{lllll}\text { FRY1/SAL1 } & 66 & \text { FSLVA } & \text { EE } & \text { DSGDLRKDGSQDTL } \\ \text { DPNP_RICE } & 73 & \text { FSMVA } & \text { EE } & \text { DSEELRKEGAEEIL } \\ \text { HAL2_YEAST } & 67 & \text { DKVVG } & \text { EE } & \text { SSSGLSDAFVSGIL } \\ \text { CYSQ_E.COLI } & 59 & \text { VPVLS } & \text { EE } & \text { DPPGWEVRQHWQRH } \\ \text { INPP_FLY } & 80 & \text { DAILG } & \text { EE } & \text { SANFTNQLGESVTI } \\ \text { INPP1_MOUSE } & \mathbf{7 4} & \text { KKVFG } & \text { EE } & \text { SNEFTNDLGEKITV } \\ \text { INPP1 HUMAN } & \mathbf{7 4} & \text { KNIFG EE } & \text { SNEFTNDWGEKITL }\end{array}$

$\mathbf{D}$

\begin{tabular}{|c|c|c|c|}
\hline & & & $(-1)$ \\
\hline 32 & YREKI & WD & HVAGAIVVTEAGG \\
\hline & YREKI & WD & HAAGSIVVTEAGG \\
\hline 88 & YQEKI & WD & HAAGNVIVHEAGG \\
\hline 99 & GPTNI & WD & TAAGHAVAAAAGA \\
\hline م & GST & WD & TCAPQAILRALGG \\
\hline & DTTYK & WD & SCAAHAILRAMGG \\
\hline & & & AHAII \\
\hline
\end{tabular}

Figure 6. Positional cloning of the FRY1. (A) Physical mapping of FRY1. On the basis of analysis of 818 recombinant chromosomes, the FRY1 locus was initially mapped to an 11-cM region on the low arm of chromosome $\mathrm{V}$ between the simple sequence length polymorphism (SSLP) markers K19B1 and MSN2. Further genetic mapping of 1968 chromosomes narrowed FRY1 to a $160-\mathrm{kb}$ region between the SSLP marker MBK5-64K and the single nucleotide polymorphism marker MJH24-48K. (B) Structure of the FRY1 gene and positions of fry1 mutations. Positions are relative to the translation initiation codon (position 36125, GenBank accession no. AB019227). Filled boxes indicate the open reading frame obtained by RT-PCR (GenBank accession no. AY034894) and lines between boxes indicate introns. $(C-D) F R Y 1$ encodes a bifunctional enzyme with inositol polyphosphate 1-phosphatases and 3'(2'),5'bisphosphate nucleotidases activities. Shown are amino acid alignments of FRY1 with other inositol polyphosphate 1-phosphatases (INPP) or $3^{\prime}\left(2^{\prime}\right), 5^{\prime}$-bisphosphate nucleotidases (DPNP) at two highly conserved regions. (C) The EE motif in the $\beta 1$ sheet. The fry1-2 mutation changes the second glutamic acid residue (E) to a lysine (K). (D) The WD-X ${ }_{11}$-GG motif in the $\alpha 5$ helix. The fry 1-1 mutation changes the tryptophan residue $(\mathrm{W})$ to a stop codon. GenBank accession nos. are as follows: FRY1/SAL1, AY034894/Q42546; DPNP_rice, Q40639; MET22/HAL2_yeast, P32179; CYSQ_Escherichia coli, P22255; INPP_fly, AAC24856; INPP_mouse, P49442; and INPP1_human, NP_002185.

blot analysis, GUS reporter gene under control of the FRY1 promoter was ubiquitously expressed in Arabidopsis seedlings (Fig. 7C-E). In leaves, FRY1::GUS expression was particularly evident in veins (Fig. 7C). It is also expressed in the primary root, root hairs (Fig. 7D), and stems (Fig. 7E; data not shown). In floral organs, FRY1::GUS expression was detected in sepals, petals, stamens, and carpels (Fig. 7E), with stamens showing the strongest expression (Fig. 7E).

To determine the impact of fry1 mutation on FRY1 enzyme activity, recombinant FRY1-GST fusion protein was tested against $3^{\prime}$-phosphoadenosine $5^{\prime}$-phosphate (PAP). Whereas wild-type FRY1 showed a strong activity toward PAP $(11.7 \pm 0.74 \mu$ mole $\mathrm{P} / \mathrm{h}$ per $\mathrm{mg}$ protein, $n=3$ ), fry1-1 mutant protein was entirely inactive, consistent with the prediction that fry1-1 is a null mutation. FRY1/SAL1 protein has been shown to be able to hydrolyze inositol 1, 4-bisphosphate $\left[\operatorname{Ins}(1,4) \mathrm{P}_{2}\right]$ and inositol 1, 3, 4-trisphosphate $\left[\operatorname{Ins}(1,3,4) \mathrm{P}_{3}\right]$ with activities about one-third of that against PAP (Quintero et al. 1996), yet its activity against inositol 1, 4, 5-trisphosphate $\left(\mathrm{IP}_{3}\right)$ was not reported. We measured the activities of wild-type FRY1 on $\mathrm{IP}_{3}$ and found that FRY1 had a low activity against $\mathrm{IP}_{3}(0.47 \pm 0.11 \mu$ mole $\mathrm{P} / \mathrm{h}$ per $\mathrm{mg}$ protein), which is $\sim 4 \%$ that of the activity against PAP. Interestingly, mutant fry1-1 protein completely lost this activity against $\mathrm{IP}_{3}$. 
A

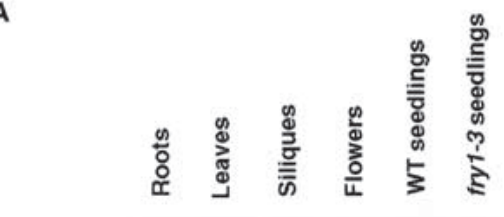

FRY1

rRNA

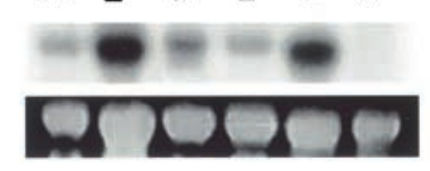

B

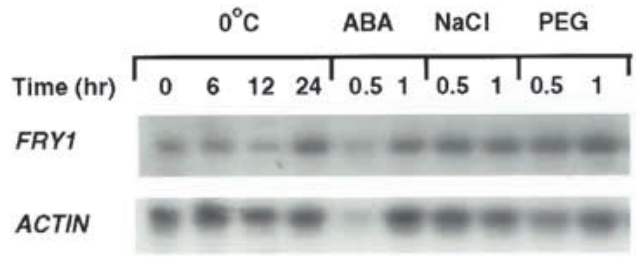

$\mathbf{E}$

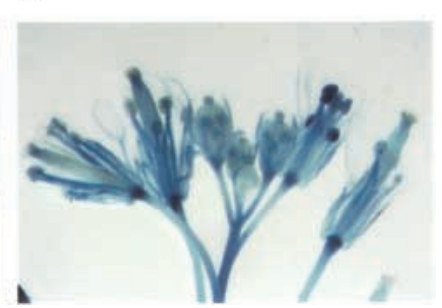

Figure 7. Expression of the FRY1 gene. (A) FRY1 transcript was detected in each plant organ examined and was absent in fry1-3 mutant plants due to T-DNA disruption. Total RNA $(20 \mu \mathrm{g})$ from indicated plant parts or from 7-day-old wild-type (WT seedlings) and fry1-3 (T-DNA allele) seedlings were resolved on 1.3\% agarose-formaldehyde gel and blotted onto a nylon membrane. The membrane was probed with ${ }^{32} \mathrm{P}$-labeled FRY1 cDNA. (B) The expression of FRY1 transcript in wild-type seedlings was not substantially regulated by stress treatment. rRNA or ACTIN was used as loading controls. (C-E) Expression of FRY1::GUS in seedling $(C)$, root and root hairs $(D)$, and in floral organs $(E)$.

\section{Increased $I P_{3}$ accumulation in fryl mutant plants}

The inositol polyphosphate 1-phosphatase activity of FRY1/SAL1 suggests that it participates in phosphoinositide signaling. Although FRY1 and its homologs in other organisms were shown to have both nucleotidase activity and inositol phosphatase activities, in multicellular organisms, FRY1 homologs mainly function as an inositol phosphatase. In animal cells, FRY1/SAL1 homologs are specific to the phosphoinositide signaling system and are primary targets of therapeutic action of $\mathrm{Li}^{+}$treatment in patients for manic-depressive disease (Majerus 1992). The inositol phosphatase activity was proposed to mediate $\mathrm{IP}_{3}$ breakdown by dephosphorylating the $\mathrm{IP}_{3}$ catabolic intermediates, $\operatorname{Ins}(1,4) \mathrm{P}_{2}$ and Ins(1,3,4) $\mathrm{P}_{3}$ (Majerus 1992). As fry1 mutant plants grow normally with inorganic sulfate as the sole sulfur source and there is no sign of sulfur deficiency (data not shown), the nucleotidase activity of FRY1 in sulfate assimilation seems to be dispensable. Thus, we hypothesized that FRY1 mainly functions as an inositol polyphosphate 1-phosphatase that mediates the catabolism of $\mathrm{IP}_{3}$.

To gain insight into the role of FRY1 in $\mathrm{IP}_{3}$ metabolism in vivo, $\mathrm{IP}_{3}$ content was determined in wild-type and fry1-1 seedlings treated with $100 \mu \mathrm{M}$ ABA. In wildtype seedlings, ABA induced a transient increase in the level of $\mathrm{IP}_{3}$, with the level of $\mathrm{IP}_{3}$ after 1 min nearly 10 times that of untreated control plants (Fig. 8). Ten min after $\mathrm{ABA}$ treatment, $\mathrm{IP}_{3}$ level returned to pretreatment levels. At 30 min after $\mathrm{ABA}$ treatment, the $\mathrm{IP}_{3}$ level was not significantly different from untreated control. fry1-1 mutant seedlings had a high level of $\mathrm{IP}_{3}$ even in the ab- sence of exogenous ABA treatment (Fig. 8). This constitutive level of $\mathrm{IP}_{3}$ is likely responsible for the low constitutive expression of RD29A-LUC (Fig. 1B) and the endogenous RD29A and COR47 transcripts (Fig. 2) in fry1 mutant plants. In response to $\mathrm{ABA}$ treatment, the $\mathrm{IP}_{3}$ level in the mutant did not increase substantially until about $30 \mathrm{~min}$. Except at $1 \mathrm{~min}$ after ABA treatment, fry1-1 mutant plants had significantly higher levels of

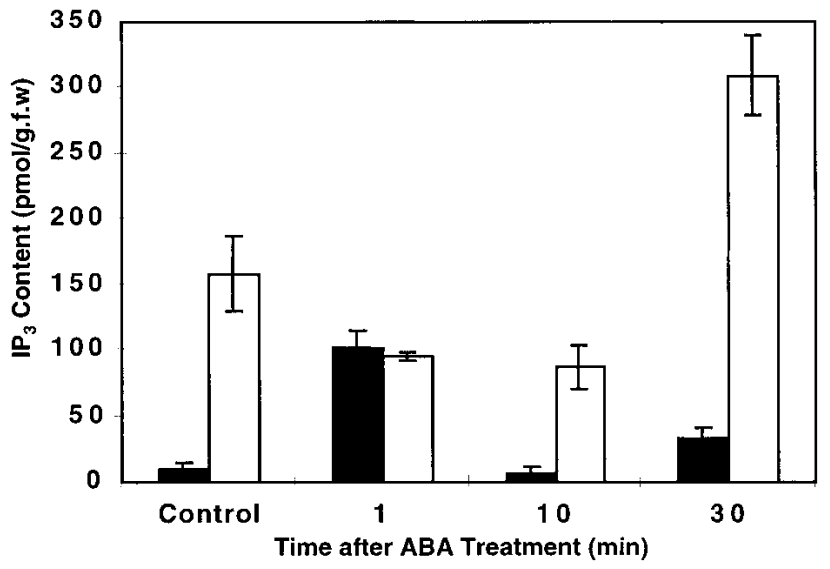

Figure 8. Changes in the level of inositol 1, 4, 5-trisphosphate $\left(\mathrm{IP}_{3}\right)$ in wild-type and fry1-1 plants in response to ABA treatment. Rosette plants grown in soil were sprayed with $100 \mu \mathrm{M}$ $\mathrm{ABA}$, leaves were then sampled at the indicated times, and $\mathrm{IP}_{3}$ measured using a receptor-binding assay as described in Materials and Methods. Error bars represent standard errors $(n=3)$. Closed bars, wild type; open bars, fry1-1. 
$\mathrm{IP}_{3}$ than wild-type plants at all the other time points (Fig. 8). These results are consistent with fry1 mutant plants having altered inositol polyphosphate 1-phosphatase activity and support our hypothesis that fry 1 mutations impair the mechanism for attenuating ABA and abiotic stress responses by blocking $\mathrm{IP}_{3}$ turnover.

\section{Discussion}

Previous genetic screens based on the inhibitory effect of ABA on seed germination have successfully identified several genetic loci important in ABA signaling, which in turn affect plant stress responses (for review, see Koornneef et al. 1998). In the present study, we used a reporter-gene approach to identify mutations that directly affect vegetative plant responses to stress and ABA. The fry1 mutants thus isolated show enhanced RD29A-LUC reporter gene expression in response to ABA or stress treatments. RNA blot analysis showed that the expression of the endogenous $R D 29 A$ and other stress-responsive genes such as KIN1, COR15A, HSP70, and $A D H$ was also significantly increased by the mutation under low temperature, osmotic stress, or ABA treatment (Fig. 2A). For reasons that are still not clear, the mutation altered the expression kinetics of some of the genes such as HSP7O and COR15A. fry1 Mutations also significantly lowered the excitatory threshold of gene induction by stress or ABA (Fig. 3A-C). Previous studies on the regulation of the diverse stress-responsive genes and our data of different expression profiles of these genes (Fig. 2) indicate that these genes are activated by different signaling pathways. The fact that FRY1 affects the expression of all these genes in one way or another suggests that it plays an important regulatory role in an early step connecting these different signal transduction pathways. Consistent with the early signaling role of FRY1, CBF2 induction by cold in fry1 mutant plants is more sustained (Fig. 2B), although this altered CBF2 expression kinetics by itself may not be sufficient to explain the elevated downstream gene expression.

Mutations in FRY1 not only increased the expression of stress-responsive genes, but also render the mutant plants more sensitive to ABA and to damage by low temperature, drought, or salt stress. Germination of fry 1 seeds is more sensitive to ABA (Fig. 4A-C). ABA also inhibits early seedling development of fry1; whereas at the same concentrations it does not significantly inhibit the development of the wild-type seedlings (Fig. 4D). Freezing stress causes more damage to fry 1 than it does to the wild-type plants. Upon freezing treatment, fry 1 plants lost more electrolytes (Fig. 5A). Likewise, fry1 plants also showed a higher sensitivity to osmotic stresses. On $\mathrm{NaCl}$ media, fry 1 plants were more damaged than were wild-type plants, as indicated by increased leaf injuries and reduced survival rate in the mutant (Fig. 5B). The increased sensitivity to mannitol (Fig. 5C) indicated that fry1 plants are sensitive to general osmotic stress. Accordingly, fry1 mutant plants are less tolerant to drought stress as indicated by increased electrolyte leakages upon treatment with PEG (Fig. 5D).
These phenotypes of fry 1 mutant plants clearly reflect important functions of wild-type FRY1 in ABA and stress responses. To our surprise, $F R Y 1$ encodes a bifunctional phosphatase with both $3^{\prime}\left(2^{\prime}\right), 5^{\prime}$-bisphosphate nucleotidase and inositol polyphosphate 1-phosphatase activities. Although mutants with lesions in FRY1-like genes in E. coli, yeast, and more recently in Drosophilia have been isolated, gene expression studies in these mutants have not been reported. The E. coli cysQ (Neuwald et al. 1992) and yeast met22/hal2 mutants (Gläser et al. 1993) were unable to reduce sulfate and need reduced or organic form of sulfur (e.g., methionine or cysteine) to grow. Additionally, the yeast met22/hal2 was also more sensitive to salt stress presumably as a result of the accumulation of PAP, which inhibits sulfate reduction and RNA processing (Gläser et al. 1993; Dichtl et al. 1997). FRY1/ SAL1 was able to complement yeast met22/hal2 mutants for their methionine auxotrophy and $\mathrm{Li}^{+} / \mathrm{Na}^{+}$sensitivity (Quintero et al, 1996). The facts that fry1 mutant plants are able to use inorganic sulfate as the sole sulfur source and do not show any sulfur-deficiency symptoms suggest that FRY1 is not required for sulfate reduction in Arabidopsis, perhaps because there are five FRY1-like genes in the Arabidopsis genome (data not shown). Among Arabidopsis FRY1-like proteins, the product encoded by AT4g05090 (GenBank accession no. CAB81051) on chromosome IV, is most closely related to MET22/HAL2 (data not shown), suggesting that the AT4g05090 product likely functions in sulfate reduction in Arabidopsis. Despite their sequence similarities, FRY1-like proteins in the unicellular organisms, E. coli and yeast do not have inositol polyphosphate 1-phosphatase activities (Neuwald et al. 1992; Murguia et al. 1995), contrasting with those in multicellular organisms in which 1-phosphatase activity has been shown both in plants and in animal systems (e.g., Quintero et al. 1996; York et al. 1995). Phylogenetic analysis also reveals that FRY1 is more closely related to its animal homologs than to either the bacterial or yeast counterparts (data not shown). Therefore, the defect in phosphoinositol 1 -phosphatase function is most likely responsible for the fry1 mutant phenotypes.

It has been established that phosphoinositides are involved in many signal transduction processes in animal systems. A generic scheme depicts that the activation of receptors activates specific phospholipases that function in the breakdown of phosphotidylinositol 4,5-bisphosphate $\left(\mathrm{PIP}_{2}\right)$, generating the second messengers inositol 1,4,5-trisphosphate and diacylgercerol. Inositol 1,4,5trisphosphate $\left(\mathrm{IP}_{3}\right)$ was shown to trigger $\mathrm{Ca}^{2+}$ release from internal stores in many cell types. In plants, exogenous $\mathrm{IP}_{3}$ was shown to release $\mathrm{Ca}^{2+}$ from vacuolar vesicles or isolated vacuoles (e.g., Schumaker and Sze 1987) and to mediate transient increases in cytosolic $\mathrm{Ca}^{2+}$ (e.g., Allen et al. 1995). Both $\mathrm{IP}_{3}$ and $\mathrm{Ca}^{2+}$ have been implicated in ABA and environmental stress responses (for reviews, see Munnik et al. 1998; Sanders et al. 1999). In response to $\mathrm{ABA}$ treatment, there is a transient increase in $\mathrm{IP}_{3}$ in guard cell protoplasts of Vicia faba (Lee et al. 1996). $\mathrm{IP}_{3}$ transients have also been observed in 
cells in response to hyperosmotic stress (Heilmann et al. 1999|. These results and our finding that FRY1 encodes an enzyme with inositol polyphosphate 1-phosphatase activity led us to hypothesize that the role of FRY1 is in the attenuation of ABA and stress responses by controlling the turnover of the second messenger $\mathrm{IP}_{3}$. That is, the initial perception of ABA or abiotic stress by plants results in a transient increase in $\mathrm{IP}_{3}$. The amplitude of this signal is attenuated by inositol polyphosphate 1-phosphatase mediated breakdown of $\mathrm{IP}_{3}$. This does not occur in fry 1 mutants, which results in sustained $\mathrm{IP}_{3}$ and perhaps other inositol polyphosphate levels and enhanced expression of stress-responsive genes. To test this hypothesis, we determined $\mathrm{IP}_{3}$ levels in wild-type and fry 1 mutant seedlings. Our results show that fry 1 mutants accumulated higher levels of $\mathrm{IP}_{3}$ when treated with ABA (Fig. 8), indicating that FRY1 does play a role in the catabolism of $\mathrm{IP}_{3}$ in plants. Interestingly, the basal $\mathrm{IP}_{3}$ content in fry 1 mutant plants before ABA treatment was also significantly higher than that in the wild type (Fig. 8), which may have resulted from mild stress on the growth medium. This basal level of $\mathrm{IP}_{3}$ may be responsible for the constitutive RD29A-LUC expression shown in Figure $1 \mathrm{~B}$ and the constitutive expression of several stress-responsive genes in the absence of stress or ABA treatment (Fig. 2).

Given the important role of $\mathrm{IP}_{3}$ in cell signaling, the level of this molecule, not surprisingly, is tightly regulated. The biochemical pathways of $\mathrm{IP}_{3}$ catabolism have been intensively studied in vitro in animal systems. It is known that there are two major routes that mediate $\mathrm{IP}_{3}$ breakdown. These are the 5-phosphatase pathway and the 3-kinase pathway, resulting in the accumulation of $\operatorname{Ins}(1,4) \mathrm{P}_{2}$ and inositol 1,3,4,5-tetraphosphate $\left[\right.$ Ins $\left.(1,3,4,5) \mathrm{P}_{4}\right]$ intermediates, respectively (Majerus et al. 1992). Ins $(1,3,4,5) \mathrm{P}_{4}$ can be further dephosphorylated by 5-phosphatases to generate inositol 1,3,4-trisphosphate $\left[\right.$ Ins $\left.(1,3,4) \mathrm{P}_{3}\right]$. In animal cells, inositol polyphosphate 1-phosphatase (IPP) was shown to hydrolyze the intermediate products of the $\mathrm{IP}_{3}$ degradation pathways, Ins $(1,4) \mathrm{P}_{2}$ and Ins $(1,3,4) \mathrm{P}_{3}$, at the 1-position (Majerus et al. 1992). FRY1/SAL1 was also able to hydrolyze both of these two inositol polyphosphates (Quintero et al. 1996). Although IPP isoforms can hydrolyze $\mathrm{IP}_{3}$ directly in certain cell types, in many other cells, the 1-phosphatase does not have this activity to directly hydrolyze $\mathrm{IP}_{3}$ (Majerus et al. 1992). Our assay of FRY1 activity against $\mathrm{IP}_{3}$ indicated that the recombinant protein had about $4 \%$ activity on $\mathrm{IP}_{3}$ relative to its activity on PAP, and impressively, fry1-1 mutation also abolished this activity. It is not known whether FRY1 needs some cofactors for full activity against $\mathrm{IP}_{3}$ or whether this low activity of FRY1 against $\mathrm{IP}_{3}$ as measured in vitro has any biological significance. Further clarification of these uncertainties in the future would shed light on the biochemical specificity of FRY1 function. Nonetheless, the 1-phosphatase activity of FRY1 toward Ins $(1,4) \mathrm{P}_{2}$ and Ins $(1,3,4) \mathrm{P}_{3}$ would inevitably affect the catabolism of $\mathrm{IP}_{3}$ as the accumulation of these intermediates would prevent the $\mathrm{IP}_{3}$ degradation pathway from going forward and result in the slowdown of $\mathrm{IP}_{3}$ degradation. It should be pointed out, however, that an enhanced accumulation of $\mathrm{IP}_{3}$ alone might not account for all the enhanced expression of stress-responsive genes and the altered stress sensitivity in the mutant. The reasons are twofold. First, from the $\mathrm{IP}_{3}$ degradation pathways, one can predict that a defect in FRY1 might also result in the accumulation of Ins $(1,3,4,5) \mathrm{P}_{4}$. Ins $(1,3,4,5) \mathrm{P}_{4}$ is also a signal in animal cells that gates $\mathrm{Ca}^{2+}$ influx into the cell and may also potentiate the effect of $\mathrm{IP}_{3}$ in releasing $\mathrm{Ca}^{2+}$ from internal stores (Shears 1998). Studies also suggested that Ins $(1,3,4) \mathrm{P}_{3}$ is a strong inhibitor of Ins $(3,4,5,6)-1$ kinase; whereas Ins $(3,4,5,6) \mathrm{P}_{4}$ is an inhibitor of $\mathrm{Ca}^{2+}$-regulated $\mathrm{Cl}^{-}$secretion (Shears 1998). Thus, Ins $(1,3,4) \mathrm{P}_{3}$ may indirectly regulate cellular ion homeostasis in vivo (Shears 1998). In yeast, FRY1/SAL1 increases salt tolerance of the yeast transformants probably by increasing the efflux of $\mathrm{Li}^{+} / \mathrm{Na}^{+}$(Quintero et al. 1996). This process may involve phosphoinositide signaling because inhibition of phospholipase C reduces $\mathrm{Li}^{+}$efflux (Quintero et al. 1996). Therefore, fry 1 mutations may cause the disruption of ion homeostasis that is required for cell adaptation to various stresses. Second, a disruption of FRY1 activity is likely to alter the dynamics of more highly phosphorylated inositols such as $\mathrm{IP}_{5}$ and $\mathrm{IP}_{6}$, signals that have been shown to affect mRNA export and gene expression (e.g., Odom et al. 2000). In plants, it was recently reported that ABA elicits a rapid increase in $\mathrm{IP}_{6}$ level, and $\mathrm{IP}_{6}$ was shown to inhibit $\mathrm{Ca}^{2+}$-dependent inward $\mathrm{K}^{+}$currents in guard cells of Solanum tuberosum and Vicia faba (Lemtiri-Chlieh et al. 2000).

Although phosphoinositols have been implicated by biochemical and molecular studies to play roles in stress and ABA signal transduction, our results provide the first genetic evidence that phosphoinositols mediate gene regulation by cold, drought, and salt stress, as well as by ABA. Mutations in FRY1 result in significantly higher induction of ABA and stress-regulated gene expression (Figs. 1,2), indicating that the wild-type FRY1 protein attenuates these signaling pathways. This early attenuation mechanism is an important aspect of signal transduction to prevent overactivation of downstream pathways. Moreover, this attenuation mechanism is also critical to maintain resistance to the abiotic stresses since fry 1 mutant plants are compromised in stress tolerance (Fig. 5). This indicates that a deregulated $\mathrm{IP}_{3}$ metabolism can have a dramatic negative effect on plant tolerance to environmental stresses, despite an enhanced expression of stress-responsive genes (Fig. 2). These findings differ from some transgenic studies where enhanced expression of stress-responsive genes in plants overexpressing CBF/DREB1 transcription factors increased plant tolerance to various abiotic stresses (e.g., Jaglo-Ottosen et al. 1998; Kasuga et al. 1999). These apparent discrepancies may result from some as-yet-unknown determinants. It is notable that FRY1 manifests its effect in early steps of signal transduction. Hence, in addition to the signaling roles of other phosphoinositols and their regulation of ion-channel activities as discussed above, the defect in early steps of signaling may impair some 
yet-unknown signaling branches that might be required for stress tolerance.

\section{Materials and methods}

\section{Isolation of fry1 mutants}

Transgenic Arabidopsis thaliana of the C24 ecotype expressing the RD29A-LUC transgene (referred to as the wild type) were obtained by Agrobacterium-mediated transformation (Ishitani et al. 1997). The wild-type RD29A-LUC plants were mutagenized by ethyl methanesulfonate (Ishitani et al. 1997) or by transformation with Agriobacterium tumefaciens strain GV3101 carrying the pSKI015 activation tagging vector (Weigel et al. 2000). $M_{2}$ or $T_{2}$ seeds were planted on $0.6 \%$ agar plates containing full strength MS salt base (JRH Biosciences) and 1-week-old seedlings were screened for abnormal LUC expression in response to low temperature, $\mathrm{ABA}$, or osmotic stress with a thermoelectrically cooled CCD camera. For ABA treatment, $( \pm)$-cis, trans-abscisic acid in $\mathrm{H}_{2} \mathrm{O}$ was sprayed uniformly on the leaves of seedlings and the plants were incubated at room temperature under cool-white light before luminescence imaging. For $\mathrm{NaCl}$ or PEG treatment, seedlings on MS plates were transferred to filter paper saturated with MS solution supplemented with $300 \mathrm{mM} \mathrm{NaCl}$ or $30 \%$ of polyethylene glycol (molecular mass 6000). For luminescence imaging, plants were sprayed uniformly with $1 \mathrm{mM}$ luciferin in $0.01 \%$ Triton X-100 and then kept in the dark for 5 min before imaging. All images were acquired with 5-min exposure time. The luminescence intensity of each seedling was quantified with the WinView software.

\section{RNA analysis}

Ten-day-old seedlings grown on MS agar plates were treated with either low temperature, $\mathrm{ABA}, \mathrm{NaCl}$, or PEG. Respective treatment conditions were as stated in the text. Total RNA from control or treated plants was extracted and analyzed as described (Ishitani et al. 1998). Gene-specific probes were as described (Ishitani et al. 1998; Lee et al. 2001).

\section{Germination assay}

One hundred seeds from wild-type and fry1-1 plants in triplicates were placed on filter paper saturated with distilled water or different concentrations of $\mathrm{ABA}$ or $\mathrm{NaCl}$ and incubated at $0^{\circ} \mathrm{C}$ for $48 \mathrm{~h}$ before being placed at room temperature under cool-white light for germination. Seeds were considered as germinated when radicles completely penetrated the seed coat. Germination was scored daily up to $10 \mathrm{~d}$ after being placed at room temperature.

\section{Stress tolerance}

For salt or drought tolerance assay, wild-type and fry1-1 seeds were planted on MS agar plates for germination. Two days after germination, 80 seedlings from each line were carefully transferred to a new MS agar plate supplemented with different concentrations of $\mathrm{NaCl}$ or mannitol. There were three replicates for each treatment. After growing for ten days in the treatment media, plants with yellowish (i.e., damaged) or dead cotyledons were scored. The fresh weight and dry weight of the seedlings were measured. For freezing tolerance assay, fry1-1 and wildtype seeds were sown in soil. For cold acclimation treatment, plants at the rosette stage were placed at $4^{\circ} \mathrm{C}$ under white fluo- rescent light for one week before sampling the leaves for freezing tolerance assay. Fully developed rosette leaves were used to determine freezing-caused electrolyte leakage as previously described (Ishitani et al. 1998).

To measure ion leakage in seedlings induced by PEG treatment, 1-week-old wild-type and fry1-1 seedlings growing in MS agar plates were carefully removed from the plate and placed in solutions containing different concentrations of polyethylene glycol (PEG) (molecular mass 6000) for $5 \mathrm{~h}$. After the treatment, seedlings were rinsed briefly in distilled water and immediately placed in a tube with $3 \mathrm{~mL} \mathrm{H}_{2} \mathrm{O}$. The tube was then agitated for $3 \mathrm{~h}$ before electrolyte content was measured. Four replicates of each treatment were conducted.

\section{$I P_{3}$ assay}

Soil-grown wild-type and fry1-1 plants at the rosette stage were sprayed with $100 \mu \mathrm{M} \mathrm{ABA}$ and leaves were excised at 1, 10, and 30 min after ABA treatment and immediately frozen in liquid nitrogen. After being ground in liquid nitrogen, the samples were extracted with $20 \%$ perchloric acid and supernatants collected after centrifugation at $2000 \mathrm{~g}$ for $15 \mathrm{~min}$ at $4^{\circ} \mathrm{C}$. The supernatants were neutralized to $\mathrm{pH} 7.5$ with $\mathrm{KOH}$, and then the $\mathrm{IP}_{3}$ content was measured by the bovine adrenal binding protein assay using a $\left[{ }^{3} \mathrm{H}\right] \mathrm{IP}_{3}$ assay kit following manufacturer's instructions (Amersham Pharmacia Biotech).

\section{Cloning of FRY1}

For genetic mapping of the fry1 mutation, fry1-1 was crossed with wild-type plants of the Columbia ecotype. The resulting $F_{1}$ plants were allowed to self and homozygous fry1 mutants in the segregating $\mathrm{F}_{2}$ population were selected based on their cold- and ABA-hypersensitive luminescence. Mapping of the mutation was carried out as described previously (Lee et al. 2001). For the T-DNA tagged allele, fry1-3, plant flanking DNA was cloned as described (Weigel et al. 2000). FRY1 cDNA was obtained by using reverse transcriptase-PCR (RT-PCR) and cloned into pCR2.1-TOPO cloning vector (Invitrogen) and sequenced. For phylogenetic analysis of FRY1-like proteins, the neighbor-joining method was used to construct the tree using the GENETYX 8.0 program (Software Development Co., Tokyo, Japan).

For complementation assay, a genomic fragment containing the FRY1 open reading frame along with $1070 \mathrm{bp}$ of sequence upstream the translation initiation codon (corresponding to position 36125, GenBank accession no. AB019227) was amplified from wild-type genomic DNA and inserted into the PstI-KpnI sites of the binary vector pCAMBIA1200. The plasmid was transferred to fry1-1 mutant via Agrobacterium-mediated transformation. One hundred fifty $T_{1}$ transformants were selected based on hygromycin resistance and then transferred to soil to grow to maturity. Seedlings of the $\mathrm{T}_{2}$ generation were treated with cold or ABA and the luminescence images were taken as described above.

A FRY1 promoter fragment from 1287-bp to 42-bp upstream the translation initiation codon was amplified from genomic DNA prepared from the wild-type seedlings and inserted into BamHI-HindIII sites of the binary vector pCAMBIA1381. The resulting construct was transferred into wild-type plants via Agrobacterium-mediated in planta transformation. The $\mathrm{T}_{1}$ seedlings were stained with X-Gluc for $12 \mathrm{~h}$, followed by incubating in $70 \%$ ethanol to remove chlorophyll.

\section{FRY1 recombinant protein and enzyme activity assay}

Wild-type and fry1-1 mutant cDNAs were obtained by reverse transcriptase-PCR using mRNA isolated from wild-type and 
fry1-1 plants, respectively. The resulting PCR products were cloned into pCR2.1-TOPO cloning vector (Invitrogen) and confirmed by sequencing. The plasmids were partially digested with EcoRI and SmaI and the desired inserts were cloned inframe into the bacterial expression vector pGEX-2TK. The resultant expression constructs were transferred into E. coli BL21 cells. After induction with $0.1 \mathrm{mM}$ isopropyl $\beta$-D-thiogalactopyranoside, the cells were harvested and proteins extracted by ultrasonication. Crude extracts were purified with the Gluthathione Sepharose 4B system (Pharmacia Biotech). Enzyme activity against $3^{\prime}$-phosphoadenosine $5^{\prime}$-phosphate (PAP) was assayed at $30^{\circ} \mathrm{C}$ as described (Murguia et al. 1995). For the assay of activity against $\mathrm{IP}_{3}$, inositol 1, 4, 5-trisphosphate (Sigma) was first treated with anion exchanger resin (Whatman International, Maidstone, England) to remove free phosphate and the enzyme activity was measured as described (Murguia et al. 1995).

\section{Acknowledgments}

We thank Drs. R.T. Leonard, V. Chandler, and C. Morris for critical reading of the manuscript and B. Stevenson for excellent technical assistance. Supported by NSF grants IBN-9808398 and DBI-9813360.

The publication costs of this article were defrayed in part by payment of page charges. This article must therefore be hereby marked "advertisement" in accordance with 18 USC section 1734 solely to indicate this fact.

\section{References}

Allen, G.J., Muir, S.R., and Sanders, D. 1995. Release of $\mathrm{Ca}^{2+}$ from individual plant vacuoles by both $\mathrm{InsP}_{3}$ and cyclic ADP-ribose. Science 268: 735-737.

Arenas-Huertero, F., Arroyo, A., Zhou, L., Sheen, J., and Leon, P. 2000. Analysis of Arabidopsis glucose insensitive mutants, gin5 and gin6, reveals a central role of the plant hormone ABA in the regulation of plant vegetative development by sugar. Genes \& Dev. 14: 2085-2096.

Beaudoin, N., Serizet, C., Gosti, F., and Giraudat, J. 2000. Interactions between abscisic acid and ethylene signaling cascades. Plant Cell 12: 1103-1115.

Cutler, S., Ghassemian, M., Bonetta, D., Cooney, S., and McCourt, P. 1996. A protein farnesyl transferase involved in abscisic acid signal transduction in Arabidopsis. Science 273: $1239-1241$.

Dichtl, B., Steven, A., and Tollervey, D. 1997. Lithium toxicity in yeast is due to the inhibition of RNA processing enzymes. EMBO J. 16: 7184-7195.

Finkelstein, R.R. and Lynch, T.J. 2000. The Arabidopsis abscisic acid response gene $A B I 5$ encodes a basic leucine zipper transcriptional factor. Plant Cell 12: 599-609.

Ghassemian, M., Nambara, E., Cutler, S., Kawaide, H., Kamiya, Y., and McCourt, P. 2000. Regulation of abscisic acid signaling by the ethylene response pathway in Arabidopsis. Plant Cell 12: 1117-1126.

Giraudat, J., Hauge, B.M., Valon, C., Smalle, J., Parcy, F., and Goodman, H.M. 1992. Isolation of the Arabidopsis ABI3 gene by positional cloning. Plant Cell 4: 1251-1261.

Gläser, J.-U., Thomas, D., Gaxiola, R., Montrichard, F., Surdinkerjan, Y., and Serrano, R. 1993. Salt tolerance and methionine biosynthesis in Saccharomyces cerevisiae involve a putative phosphatase gene. EMBO I. 12: 3105-3110.
Gosti, F., Beaudoin, N., Serizet, C., Webb, A.A.R., Vartanian, N., and Giraudat, J. 1999. ABIl protein phosphatase 2C is a negative regulator of abscisic acid signaling. Plant Cell 11: 1897-1909.

Heilmann, I., Perera, I.Y., Gross, W., and Boss, W.F. 1999. Changes in phosphoinositide metabolism with days in culture affect signal transduction pathways in Galdieria suphuraria. Plant Physiol. 119: 1331-1339.

Ishitani, M., Xiong, L., Stevenson, B., and Zhu, J.-K. 1997. Genetic analysis of osmotic and cold stress signal transduction in Arabidopsis: Interactions and convergence of abscisic acid-dependent and abscisic acid-independent pathways. Plant Cell 9: 1935-1949.

Ishitani, M., Xiong, L., Lee, H., Stevenson, B., and Zhu, J.K. 1998. HOS1, a genetic locus involved in cold-responsive gene expression in Arabidopsis. Plant Cell 10: 1151-1161.

Jaglo-Ottosen, K.R., Gilmour, S.J., Zarka, D.G., Schabenberger, O., and Thomashow, M.F. 1998. Arabidopsis CBF1 overexpression induces $C O R$ genes and enhances freezing tolerance. Science 280: 104-106.

Kasuga, M., Liu, Q., Miura, S., Yamaguchi-Shinozaki, K., and Shinozaki, K. 1999. Improving plant drought, salt, and freezing tolerance by gene transfer of a single stress-inducible transcriptional factor. Nature Biotech. 17: 287-291.

Koornneef, M., Leon-Kloosterziel, K., Schwartz, S.H., and Zeevaart, J.A.D. 1998. The genetic and molecular dissection of abscisic acid biosynthesis and signal transduction in Arabidopsis. Plant Physiol. Biochem. 36: 83-89.

Lee, H., Xiong, L., Gong, Z., Ishitani, M., Stevenson, B., and Zhu, J.-K. 2001. The Arabidopsis HOS1 gene negatively regulates cold signal transduction and encodes a RING finger protein that displays cold-regulated nucleo-cytoplasmic partitioning. Genes \& Dev. 15: 912-924.

Lee, Y., Choi, Y.B., Suh, J., Lee, J., Assmann, S.M., Joe, C.O., Keller, J.F., and Crain, R.C. 1996. Abscisic acid-induced phosphoinositide turnover in guard cell protoplasts of Vicia faba. Plant Physiol. 110: 987-996.

Lemtiri-Chlieh, F., MacRobbie, E.A.C, and Brearley, C.A. 2000. Inositol hexakisphosphate is a physiological signal regulating the $\mathrm{K}^{+}$-inward rectifying conductance in guard cells. Proc. Nat1. Acad. Sci. 97: 8687-8692.

Leung, J. and Giraudat, J. 1998. Abscisic acid signal transduction. Annu. Rev. Plant Physiol. Plant Mol. Biol. 49: 199-222.

Majerus, P.W. 1992. Inositol phosphate biochemistry. Annu. Rev. Biochem. 61: 225-250.

Medina, J., Bargues, M., Terol, J., Perez-Alonso, M., and Salinas, J. 1999. The Arabidopsis CBF gene family is composed of three genes encoding AP2 domain-containing proteins whose expression is regulated by low temperature but not by abscisic acid or dehydration. Plant Physiol. 119: 463-470.

Munnik, T., Irvine, R.F., and Musgrave, A. 1998. Phospholipid signaling in plants. Biochim. Biophys. Acta 1389: 222-272.

Murguia, J.R., Belles, J.M., and Serrano, R. 1995. A salt-sensitive $3^{\prime}\left(2^{\prime}\right), 5^{\prime}$-bisphosphate nucleotidase involved in sulfate activation. Science 267: 232-267.

Neuwald, A.F., Krishnan, B.R., Brikun, I., Kulakauskas, S., Suziedelis, K., Tomcsanyi, T., Leyh, T.S., and Berg, D.E. 1992. cys $Q$, a gene needed for cysteine synthesis in Escherichia coli K-12 only during aerobic growth. J. Bacteriol. 174: 415425.

Odom, A.R., Stahlberg, A., Wente, S.R., and York, J.D. 2000. A role for nuclear inositol 1,4,5-trisphosphate kinase in transcriptional control. Science 287: 2026-2029.

Quintero, F.J., Garciadeblas, B., and Rodriguez-Navarro, A. 1996. The SAL1 gene of Arabidopsis, encoding an enzyme with $3^{\prime}\left(2^{\prime}\right), 5^{\prime}$-bisphosphate nucleotide and inositol poly- 
Xiong et al.

phosphate 1-phosphatase activities, increases salt tolerance in yeast. Plant Cell 8: 529-537.

Sanders, D., Brownlee, C., and Harper, J.F. 1999. Communicating with calcium. Plant Cell 11: 691-706.

Schumaker, K.S. and Sze, H. 1987. Inositol 1, 4, 5-trisphosphate releases $\mathrm{Ca}^{2+}$ from vacuolar membrane vesicles of oat roots. J. Biol. Chem. 262: 3944-3946.

Shears, S.B. 1998. The versatility of inositol phosphates as cellular signals. Biochim. Biophys. Acta 1436: 49-67.

Sheen, J. 1998. Mutational analysis of protein phosphatase 2C involved in abscisic acid signal transduction in higher plants. Proc. Natl. Acad. Sci. 95: 975-980.

Shen, Q. and Ho, T.H.D. 1995. Functional dissection of an abscisic acid (ABA)-inducible gene reveals two independent ABA-responsive complexes each containing a G-box and a novel cis-acting element. Plant Cell 7: 295-307.

Shinozaki, K. and Yamaguchi-Shinozaki, K. 1997. Gene expression and signal transduction in water-stress response. Plant Physiol. 115: 327-334.

Weigel, D., Ahn, J.H., Blazquez, M.A., Borevitz, J.O., Christensen, S.K., Fankhauser, C., Ferrandiz, C., Kardailsky, I., Malancharuvil, E.J., Neff, M.M., et al. 2000. Activation tagging in Arabidopsis. Plant Physiol. 122: 1003-1014.

Yamaguchi-Shinozaki, K. and Shinozaki, K. 1994. A novel cisacting element in an Arabidopsis gene is involved in responsiveness to drought, low-temperature, or high-salt stress. Plant Cell 6: 251-264.

York, J.D., Ponder, J.W., and Majerus, P.W. 1995. Definition of a metal-dependent/Li+-inhibited phosphomonoesterase protein family based upon a conserved three-dimensional core structure. Proc. Natl. Acad. Sci. 92: 5149-5153.

Zhu, J.K., Hasegawa, P.M., and Bressan, R.A. 1997. Molecular aspects of osmotic stress in plants. Crit. Rev. Plant Sci. 16: $253-277$. 


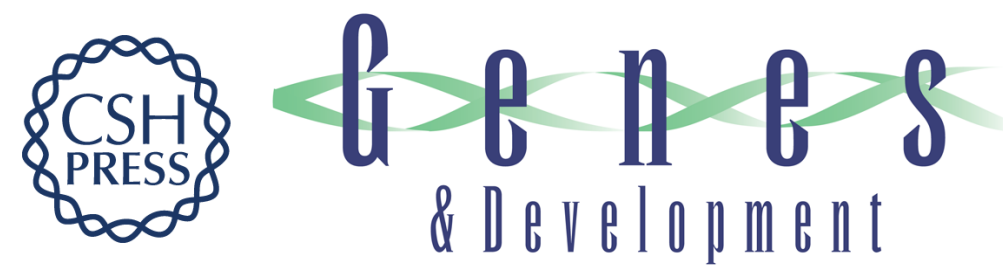

\section{FIERY1 encoding an inositol polyphosphate 1-phosphatase is a negative regulator of abscisic acid and stress signaling in Arabidopsis}

Liming Xiong, Byeong-ha Lee, Manabu Ishitani, et al.

Genes Dev. 2001, 15:

Access the most recent version at doi:10.1101/gad.891901

References This article cites 36 articles, 28 of which can be accessed free at:

http://genesdev.cshlp.org/content/15/15/1971.full.html\#ref-list-1

License

Email Alerting Receive free email alerts when new articles cite this article - sign up in the box at the top

Service right corner of the article or click here.

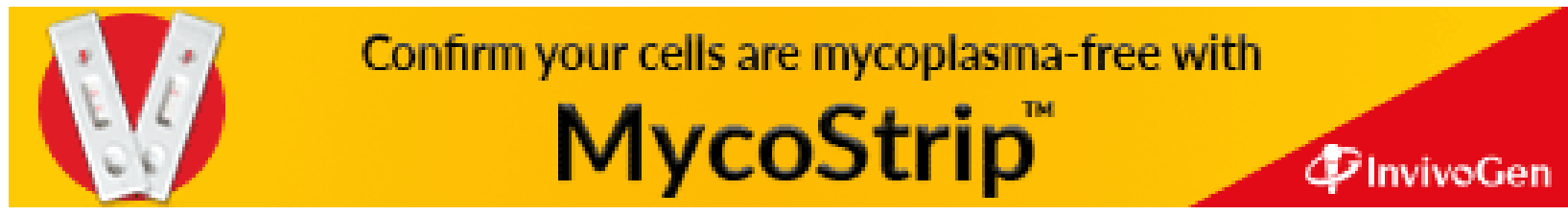

